\title{
Multiplex quantitative PCR for detection of lower respiratory tract infection and meningitis caused by Streptococcus pneumoniae, Haemophilus influenzae and Neisseria meningitidis
}

Guma MK Abdeldaim ${ }^{1}$ Kristoffer Strålin², Jens Korsgaard ${ }^{3}$, Jonas Blomberg ${ }^{4}$, Christina Welinder-Olsson ${ }^{5}$, Björn Herrmann ${ }^{1 *}$

\begin{abstract}
Background: Streptococcus pneumoniae and Haemophilus influenzae cause pneumonia and as Neisseria meningitidis they are important agents of meningitis. Although several PCR methods have been described for these bacteria the specificity is an underestimated problem. Here we present a quantitative multiplex real-time PCR (qmPCR) for detection of S. pneumoniae (9802 gene fragment), H. influenzae (omp P6 gene) and N. meningitidis (ctrA gene). The method was evaluated on bronchoalveolar lavage (BAL) samples from 156 adults with lower respiratory tract infection (LRTI) and 31 controls, and on 87 cerebrospinal fluid (CSF) samples from meningitis patients.

Results: The analytical sensitivity was not affected by using a combined mixture of reagents and a combined DNA standard (S. pneumoniae/H. influenzae/N. meningitidis) in single tubes. By blood- and BAL-culture and S. pneumoniae urinary antigen test, S. pneumoniae and $\mathrm{H}$. influenzae were aetiological agents in 21 and 31 of the LTRI patients, respectively. These pathogens were identified by qmPCR in 52 and 72 of the cases, respectively, yielding sensitivities and specificities of 95\% and 75\% for S. pneumoniae, and 90\% and 65\% for $\mathrm{H}$. influenzae, respectively. When using a cut-off of $10^{5}$ genome copies $/ \mathrm{mL}$ for clinical positivity the sensitivities and specificities were $90 \%$ and $80 \%$ for S. pneumoniae, and $81 \%$ and $85 \%$ for $\mathrm{H}$. influenzae, respectively. Of 44 culture negative but qmPCR positive for $\mathrm{H}$. influenzae, 41 were confirmed by fuck PCR as $\mathrm{H}$. influenzae. Of the 103 patients who had taken antibiotics prior to sampling, S. pneumoniae and $\mathrm{H}$. influenzae were identified by culture in $6 \%$ and $20 \%$ of the cases, respectively, and by the qmPCR in $36 \%$ and $53 \%$ of the cases, respectively.

In 87 CSF samples S. pneumoniae and N. meningitidis were identified by culture and/or 16 S rRNA in 14 and 10 samples and by qmPCR in 14 and 10 samples, respectively, giving a sensitivity of 100\% and a specificity of 100\% for both bacteria.

Conclusions: The PCR provides increased sensitivity and the multiplex format facilitates diagnosis of S. pneumoniae, H. influenzae and N. meningitidis and the assay enable detection after antibiotic treatment has been installed. Quantification increases the specificity of the etiology for pneumonia.
\end{abstract}

\section{Background}

Streptococcus pneumoniae and Haemophilus influenzae are major causes of community-acquired pneumonia (CAP) $[1,2]$ and as Neisseria meningitidis they are important agents of meningitis [3-5]. Identification of

\footnotetext{
* Correspondence: bjorn.herrmann@medsci.uu.se

'Section of Clinical Bacteriology, Department of Medical Sciences, Uppsala University, Uppsala, Sweden

Full list of author information is available at the end of the article
}

the microbiological cause of CAP and meningitis is important, as it enables pathogen-directed antibiotic therapy. Conventional detection of bacteria is based on culture and phenotypic characterization. However, culture methods are time-consuming and have relatively low sensitivity, especially when antibiotics have been given to the patient prior to sampling [6]. The use of nucleic acid amplification tests, such as quantitative real-time polymerase chain reaction (qPCR), have

\section{() Biomed Central}


enabled more sensitive and rapid detection of pathogens in respiratory secretions and cerebrospinal fluid (CSF).

Several qPCR assays for the detection of $S$. pneumoniae [7-9], H. influenzae [10-12] and N. meningitidis [13] have been developed and multiplex detection of several target DNAs in a single tube is achievable [14-16]. Still, the specificity of methods used is an underestimated problem and commonly used targets have been shown to be unspecific and causing misleading results. An illustrative example is the pneumolysin (ply) gene for the detection of S. pneumoniae [17-19]. For detection of $H$. influenzae, a species with frequent exchange of genetic elements, the problem is even worse and most target genes used are problematic. The bexA is not present in all strains of $H$. influenzae [20], while $16 S$ rRNA and $r n p B$ do not provide specific detection [21]. We have recently developed qPCRs for specific detection of S. pneumoniae, based on the Spn9802 fragment [17], and for the detection of H. influenzae, based on the outer membrane protein P6 [21]. Real time PCR assays for detection of $N$. meningitidis have been based on genes as porA [22] and $\operatorname{ctr} A[14,16]$.

Here we present a new quantitative multiplex PCR (qmPCR) method for detection of S. pneumoniae, $H$. influenzae and $N$. meningitidis. The method was evaluated on a collection of bronchoalveolar lavage (BAL) and cerebrospinal fluid specimens for detection of lower respiratory tract infection (LRTI) and meningitis due to these three bacteria species.

\section{Methods}

\section{Patients and controls}

From 1997 through 2000, 159 consecutively identified immunocompetent adult patients who were hospitalised for LRTI at the Department of Internal Medicine, Silkeborg County Hospital, Silkeborg, Denmark, were enrolled in a prospective study [23]. The criteria for LRTI were fever and/or an increased leukocyte count $\left(\geq 11 \times 10^{9} / \mathrm{L}\right)$, together with increased focal symptoms from the lower airways with at least one of three newly developed symptoms of increased dyspnoea, increased coughing and/or increased sputum purulence.

The enrolled patients underwent standardized fibreoptic bronchoscopy within 24 hours from admission. For the present study, BAL fluid was available in 156 patients, median age 63 years (range $26-90$ years). A chronic lung disease was documented in 72 patients (46\%), 31\% were current and $40 \%$ were previous smokers. New X-ray infiltrates were identified in 87 patients (56\%). Antibiotics had been taken within 7 days prior to bronchoscopy in 103 cases (66\%).

As controls, 31 adult patients, median age 64 years (range 30-77 years), who consecutively underwent fibreoptic bronchoscopy for suspected malignancy and who did not have pulmonary infection were included.
Nineteen of them had lung malignancies and 12 had no pathology identified by bronchoscopy or radiological examinations. Twenty-seven controls (87\%) were current or previous smokers.

CSF samples sent for culture to the Bacteriological Laboratory, Sahlgrenska University Hospital, Gothenburg, Sweden during a four year period were used in the study. Specimens were eligible if the total CSF white blood cell (WBC) count was $\geq 10 \times 10^{6} / \mathrm{L}$ indicating meningeal inflammation. Only one CSF sample from each patient was included. Medical records of all patients included in the study were reviewed retrospectively for a final diagnosis, predisposing factors, treatment and outcome by one doctor. All 87 specimens were included in a study previously published for $16 \mathrm{~S}$ rRNA gene PCR [24] and the relevance of the PCR findings and bacterial cultures to the final diagnosis was evaluated and compared with the clinical findings and other laboratory results. The median age of the patients were 34 years (range 1 day- 91 years).

\section{Fibre-optic bronchoscope}

In brief, the fibre-optic bronchoscope was introduced through the nose or through the mouth. The tip of the bronchoscope was wedged into the segment of bronchus affected by a pulmonary infiltrate, or, if no infiltrate was available, into the middle lobe. A sterile, thin tube was then introduced into the working channel of the bronchoscope, and lavage was then performed. One to three portions of $60 \mathrm{~mL}$ of isotonic $\mathrm{NaCl}$ were used for lavage, and the aspirated fluid was collected in one single portion for microbiological analyses.

\section{Conventional diagnostic methods}

BAL fluid from the LRTI patients and the controls were analysed with culture (but no Gram staining) at the Department of Clinical Microbiology, Aarhus University Hospital (Aalborg, Denmark), within a maximum of $6 \mathrm{~h}$ from the time of sampling. The specimens were cultured on $5 \%$ horse blood agar and chocolate agar with semiquantitative determinations by dispersion of 1 and 10 $\mu \mathrm{L}$ on each half of the plate. The plates were incubated in $5 \%$ carbon dioxide at $35^{\circ} \mathrm{C}$ for $24-48 \mathrm{~h}$.

From 152 LRTI patients, blood samples were collected for culture with a Bactec blood-culturing system (BioMérieux, Marcy-Etoile, France) at the Department of Clinical Microbiology, Aarhus University Hospital. Non-frozen urine samples collected from 142 LRTI patients were sent to the Department of Bacteriology, Mycology and Parasitology, Statens Serum Institute, Copenhagen, Denmark, and were analyzed for pneumococcal capsular polysaccharides by countercurrent immunoelectrophoresis [25].

CSF samples were submitted for routine bacterial culture and chemistry [26]. 


\section{DNA extraction}

DNA from 0.2-0.5 mL BAL was extracted by the automatic MagNa Pure LC DNA-Isolation system (Roche Diagnostics). Bacteria DNA used for determination of the analytical sensitivity of the Spn9802 and the P6 PCRs was purified from cultured isolates (S. pneumoniae CCUG $28588^{\mathrm{T}}$ and $H$. influenzae CCUG $23946^{\mathrm{T}}$ ) by phenol-chloroform extraction of bacteria harvested in exponential growth phase after culturing on chocolate agar at $37^{\circ} \mathrm{C}$ in $5 \%$ carbon dioxide and the concentration of DNA was determined by a Nanodrop instrument (NanoDrop Technologies, Inc. Wilmington, DE, USA). The genome copy number was determined according to conventional calculations based on molecular weight and one gene copy per genome.

CSF samples $(50 \mu \mathrm{L}-1.5 \mathrm{~mL})$ were centrifuged at $12000 \mathrm{~g}$ for $20 \mathrm{~min}$, after which DNA was extracted from the pellet with a bacterial DNA preparation kit (Roche Diagnostics, Indianapolis, USA), used according to the manufacturer's instructions.

\section{qmPCR}

The quantitative Spn9802 PCR for the detection of S. pneumoniae [17] was combined with the P6 PCR for the detection of $H$. influenzae [21] and the ctrA PCR for the detection of Neisseria meningitidis [14]. All primers and probes are shown in Table 1 where positions with lower case letters indicate locked nucleic acid [27].

The PCR for detection of $N$. meningitidis was used as described previously, except that $3.5 \mathrm{mmol} / \mathrm{L} \mathrm{MgCl}_{2}$ was used instead of $5.5 \mathrm{mmol} / \mathrm{L}$ and that the elongation time was $40 \mathrm{~s}$ instead of $1 \mathrm{~min}$. All primers and probes were obtained from Thermo Hybaid, Interactiva Division (Ulm, Germany) except the Spn9802 FAM probe which was obtained from Eurogentec, Seraing, Belgium.
The real-time PCR assay was performed in a RotorGene 3000 instrument (Qiagen, Hilden, Germany). The optimized real-time PCR amplifications were performed in $25-\mu \mathrm{L}$ reactions containing $0.3 \mu \mathrm{mol} / \mathrm{L}$ of each primer, $0.2 \mu \mathrm{mol} / \mathrm{L}$ of the Spn9802 FAM probe, $0.1 \mu \mathrm{mol} / \mathrm{L}$ of the P6 JOE probe and ctrA ROX probe, $3.5 \mathrm{mmol} / \mathrm{L} \mathrm{MgCl}_{2}, 0.2 \mathrm{mmol} / \mathrm{L}$ deoxynucleoside triphosphate, and $1 \mathrm{U}$ HotStar Taq polymerase (Qiagen) in PCR buffer. A total of $5 \mu \mathrm{L}$ of target DNA was used in the assay. The qmPCR was performed according to the following program: 15 min of enzyme activation at $95^{\circ} \mathrm{C}$, followed by 45 cycles of $95^{\circ} \mathrm{C}$ for $15 \mathrm{~s}$ and $60^{\circ} \mathrm{C}$ for $40 \mathrm{~s}$.

Reproducibility of analytical sensitivity and quantification The analytical sensitivity of the Spn9802, P6 and $\operatorname{ctr} A$ PCRs was determined by serial dilutions of target DNA in carrier tRNA $(1 \mu \mathrm{g} / \mathrm{mL})$. Two experiments were performed with 5 to 600 genome copies per reaction tube and 2 to 4 tubes of each dilution.

The reproducibility of quantification was evaluated by testing DNA preparations with known concentrations (duplicates of 500, 2,000 and 10,000 genome copies per PCR reaction) in five consecutive runs and also in 73 BAL samples and in 8 CSF samples. PCRs with primer/ probe reagents in both monoplex and multiplex were tested in parallel. In addition we tested the reproducibility of quantification with positive control DNA of $S$. pneumoniae, $H$. influenzae and $N$. meningitidis in separate tubes and combined in a single tube.

\section{fuck PCR}

The fucK PCR was used as previously described [28], to confirm the presence of $H$. influenzae in samples which proved negative by culture but positive by qmPCR.

Table 1 Oligonucleotide primers and probes for detection of S. pneumoniae, H. influenzae and N. meningitidis.

\begin{tabular}{|c|c|c|}
\hline & Sequence $\left(5^{\prime} \text { to } 3^{\prime}\right)^{a}$ & Positions in target gene \\
\hline \multicolumn{3}{|l|}{ S. pneumoniae } \\
\hline Spn9802 F & 5'-A GTC GTT CCA AGG TAA CAA GTC T-3' & 3370-3392 \\
\hline Spn9802 R & 5'-AC CAA CTC GAC CAC CTC TाT-3' & 3525-3506 \\
\hline Spn9802 FAM & 5'-FAM_-aTc AGa TTg CTg ATa AAa CgA- ${ }^{B H Q 1}$-'3 & \\
\hline \multicolumn{3}{|l|}{ H. influenzae } \\
\hline Hi P6 F & 5'-CCA GCT GCT AAA GTA TTA GTA GAA G-3' & $302-326$ \\
\hline Hi P6 R & 5'-TTC ACC GTA AGA TAC TGT GCC-3' & $477-457$ \\
\hline Hi P6 JOE & 5'-_OE & \\
\hline \multicolumn{3}{|l|}{ N. meningitidis } \\
\hline $\operatorname{ctrA} F$ & 5'-GCTGCGGTAGGTGGTTCAA-3' & $617-635$ \\
\hline ctrA R & 5'-TTGTCGCGGATTTGCAACTA-3' & 727-708 \\
\hline ctrA ROX & 5'-ROX_CATTGCCACGTGTCAGCTGCACAT- BHQ1_'3 & \\
\hline
\end{tabular}

${ }^{a}$ Positions with lower case letters indicate locked nucleic acid [27]. 


\section{lytA PCR}

For respiratory samples the lytA PCR was tested in a gel based PCR for $S$. pneumoniae as previously described [29]. In short, extracted DNA $(10 \mu \mathrm{L})$ was added to a PCR mixture, and after 40 cycles, PCR products were detected on ethidium bromide-stained agarose gels. By serial dilution of bacterial strains, the detection level of lytA PCR has been shown to be $10^{2}$ colony forming units $(\mathrm{CFU}) / \mathrm{mL}$ sample [29].

\section{S rRNA PCR for CSF samples}

The primers and other PCR conditions used to amplify the 5'-half of the $16 S$ rRNA gene were previously described [24]. The PCR product was visualized in an agarosegel and DNA bands of expected size were cut from the gel, purified with a Qiaquick Gel Extraction kit (Qiagen) and subjected to cycle sequencing using the ABI prism Big Dye Terminator Sequencing Ready Reaction kit, v.1.1 (Applied Biosystems). The sequencing reaction products were analyzed using an ABI PRISM 310 Genetic Analyser (Applied Biosystems). After DNA sequence editing, the GenBank BLAST program was used for sequence comparisons.

\section{Ethics}

The study was performed according to the Declaration of Helsinki II and approved by the local ethical committee and all participating patients gave written consent.

\section{Results}

A sensitive and specific multiplex PCR for quantitative detection of S. pneumoniae, H. influenzae and N. meningitidis was developed and evaluated on BAL samples from adults with LRTI and a control group, and on CSF samples from patients with meningitis. To establish the detection capacity of the Spn9802, the P6 and the ctrA assays, serial dilutions of target DNA with known concentration were repeatedly tested and the analytical sensitivity was 10-60 copies per PCR reaction for the Spn9802 assay, 3-30 copies per PCR reaction for the P6 assay and 5-50 copies per PCR reaction for the ctrA assay. As shown in Table 2 the analytical sensitivity and quantification was not affected by using a combined mixture of reagents and a combined DNA standard (S. pneumoniae, $H$. influenzae and $N$. meningitidis) in single tubes.

Table 3A shows results of tests for S. pneumoniae and $H$. influenzae in the patient group. Of 156 LRTI patients S. pneumoniae was identified by conventional tests in $21(13 \%)$ cases, and by qmPCR in $54(35 \%)$ cases, including 47 cases using a cut-off level of $10^{5}$ copies $/ \mathrm{mL}$.

From the 21 patients with conventional (blood culture, BAL culture, or urinary antigen test) tests positive for $S$. pneumoniae, 20 were positive by qmPCR. In addition 34 cases with no conventional test positive for S. pneumoniae were positive with Spn9802 PCR of which 26 were

Table 2 Detection capacity of multiplex quantitative PCR

\begin{tabular}{|c|c|c|c|c|c|c|c|}
\hline \multicolumn{3}{|l|}{ Oligos for a single target } & \multicolumn{3}{|l|}{ Oligos for three targets } & \multirow{2}{*}{$\begin{array}{l}\Delta \\
C t\end{array}$} & \multirow{2}{*}{$\begin{array}{l}\Delta \text { copy number } \\
(\log 10)\end{array}$} \\
\hline $\begin{array}{l}\text { DNA standard copy } \\
\text { number } \\
\text { of target DNA (number } \\
\text { of reactions) }\end{array}$ & $\begin{array}{l}\text { Mean } C t \\
\text { value }\end{array}$ & $\begin{array}{l}\text { Mean } \\
\text { measured } \\
\text { copy } \\
\text { number } \\
(\log 10)\end{array}$ & $\begin{array}{l}\text { DNA standard } S \text {. } \\
\text { pneumoniae, } \\
H \text {. influenzae and } N \text {. } \\
\text { meningitidis } \\
\text { copy number of each } \\
\text { target DNA }\end{array}$ & $\begin{array}{l}\text { Mean } C t \\
\text { value }\end{array}$ & $\begin{array}{l}\text { Mean measured copy } \\
\text { number (log10) }\end{array}$ & & \\
\hline Spn $10000(5)$ & 27.7 & & & 27.8 & & 0.1 & \\
\hline Spn $2000(5)$ & 30.2 & & & 30.4 & & 0.2 & \\
\hline Spn $500(7)$ & 32.7 & & & 32.4 & & -0.3 & \\
\hline Hi $10000(5)$ & 23.8 & & & 23.7 & & -0.1 & \\
\hline Hi 2000 (5) & 26.4 & & & 26.4 & & 0.0 & \\
\hline Hi 500 (7) & 28.6 & & & 28.5 & & -0.1 & \\
\hline Mc 10000 (4) & 27.6 & & & 27.4 & & -0.2 & \\
\hline Mc 2000 (4) & 30.5 & & & 30.0 & & -0.5 & \\
\hline Mc $500(6)$ & 32.5 & & & 32.3 & & -0.3 & \\
\hline Spn (23 clinical samples) & $27.7 \pm 7.6$ & $3.9 \pm 1.8$ & & $28.2 \pm 7.6$ & $3.8 \pm 2.0$ & 0.5 & -0.1 \\
\hline Hi (50 clinical samples) & $\begin{array}{l}24.1 \pm \\
10.7\end{array}$ & $3.9 \pm 2.8$ & & $24.7 \pm 7.6$ & $3.8 \pm 3.0$ & 0.6 & -0.1 \\
\hline Mc (8 clinical samples) & $22.0 \pm 1.9$ & $5.2 \pm 0.5$ & & $22.2 \pm 2.0$ & $5.2 \pm 0.5$ & 0.2 & 0 \\
\hline
\end{tabular}

$\mathrm{Ct}=$ Cycle of threshold; $\mathrm{Spn}=\mathrm{S}$. pneumoniae; $\mathrm{Hi}=\mathrm{H}$. influenzae; $\mathrm{Mc}=\mathrm{N}$. meningitidis

Comparison of using PCR reaction mix with a single DNA standard and oligos for one target organism versus triplex DNA target standard and oligos for 3 target organisms. 
Table 3 Comparison of reference tests with quantitative multiplex PCR (qmPCR)

\begin{tabular}{|c|c|c|c|}
\hline \multicolumn{2}{|l|}{ Results } & \multirow[b]{2}{*}{$\begin{array}{c}\text { No. of } \\
\text { patients }\end{array}$} & \multirow[b]{2}{*}{$\begin{array}{l}\text { No. on antibiotic } \\
\text { treatment }\end{array}$} \\
\hline $\begin{array}{l}\text { Reference tests } \\
\text { a }\end{array}$ & $\mathrm{qmPCR}^{\mathrm{b}}$ & & \\
\hline \multicolumn{4}{|l|}{ A. } \\
\hline Spn \& Hi & Spn \& Hi & 1 & 1 \\
\hline Spn \& Hi & $\mathrm{Hi}$ & 1 & 1 \\
\hline Spn & Spn \& Hi & 5 & 4 \\
\hline Spn & Spn & 14 & 6 \\
\hline- & Spn & 20 & 15 \\
\hline- & Spn \& Hi & 9 & 7 \\
\hline $\mathrm{Hi}$ & Spn \& Hi & 5 & 5 \\
\hline $\mathrm{Hi}$ & $\mathrm{Hi}$ & 21 & 12 \\
\hline $\mathrm{Hi}$ & - & 3 & 3 \\
\hline- & $\mathrm{Hi}$ & 30 & 26 \\
\hline- & - & 47 & 24 \\
\hline \multicolumn{4}{|l|}{ B. } \\
\hline Spn & $\mathrm{Hi}$ & 1 & \\
\hline Spn & Spn & 1 & \\
\hline $\mathrm{Hi}$ & Spn \& Hi & 1 & \\
\hline $\mathrm{Hi}$ & $\mathrm{Hi}$ & 2 & 1 \\
\hline- & Spn & 3 & 1 \\
\hline- & Spn \& Hi & 3 & \\
\hline- & $\mathrm{Hi}$ & 4 & \\
\hline- & - & 16 & 1 \\
\hline
\end{tabular}

${ }^{a}$ Blood culture, urinary antigen test, and BAL culture for S. pneumoniae; blood culture and BAL culture for $H$. influenzae.; -, negative test result.

${ }^{\text {b }}$ Spn9802+ was considered as S. pneumoniae+; P6+ was considered as H. influenzae+.

Results of reference tests and gmPCR for Streptococcus pneumoniae (Spn) and Haemophilus influenzae (Hi) applied to bronchoalveolar lavage (BAL) samples in 156 patients with lower respiratory tract infection (A) and in 31 control patients (B). also positive by lytA PCR. Of the 6 patients with pneumococcal bacteraemia, S. pneumoniae was identified by BAL culture in one case, by urinary antigen test in one case, and by qmPCR and lytA PCR in all the 6 patients. Similarly, among the 9 patients with positive urinary antigen test, $S$. pneumoniae was identified in 8 by BAL qmPCR and in seven by lyt $A$ PCR, and none by BAL culture.

H. influenzae was not found in any blood culture but was detected by BAL culture in 31 cases, of which 28 also were positive by qmPCR. Of 44 cases proved negative by culture but positive by qmPCR, 41 were confirmed by fucK PCR.

Among the 31 control patients S. pneumoniae and $H$. influenzae were identified by BAL culture in $2(6 \%)$ and $3(10 \%)$ cases respectively, by qmPCR in $8(26 \%)$ and $11(35 \%)$ cases (Table 3B). Of 7 and 8 cases proved negative by culture but positive with qmPCR for $S$. pneumoniae and $H$. influenzae respectively, 2 were positive by lytA PCR for S. pneumoniae and 7 were positive by fucK PCR for $H$. influenzae.

Figure 1 shows the qmPCR copy number of the LRTI patients and controls compared to results by culture, urinary antigen test and lytA PCR. Among the qmPCR positive subjects, the LRTI patients and controls had a similar mean $\log 10$ of copy number 5.69 (standard deviation [SD] 1.53) versus 5.65 (SD 1.63); $p=0.79$, for H. influenzae and 6.31 (SD 1.12) versus 5.93 (SD 0.96); $p=0.36$, for S. pneumoniae). If the cut-off limit for a positive qmPCR result was risen to $10^{5}$ DNA copies $/ \mathrm{mL}$, the positivity rate among the controls would drop from $26 \%(8 / 31)$ to $16 \%(5 / 31)$ for S. pneumoniae and from $35 \%(11 / 31)$ to $19 \%(6 / 31)$ for $H$. influenzae. Similarly in

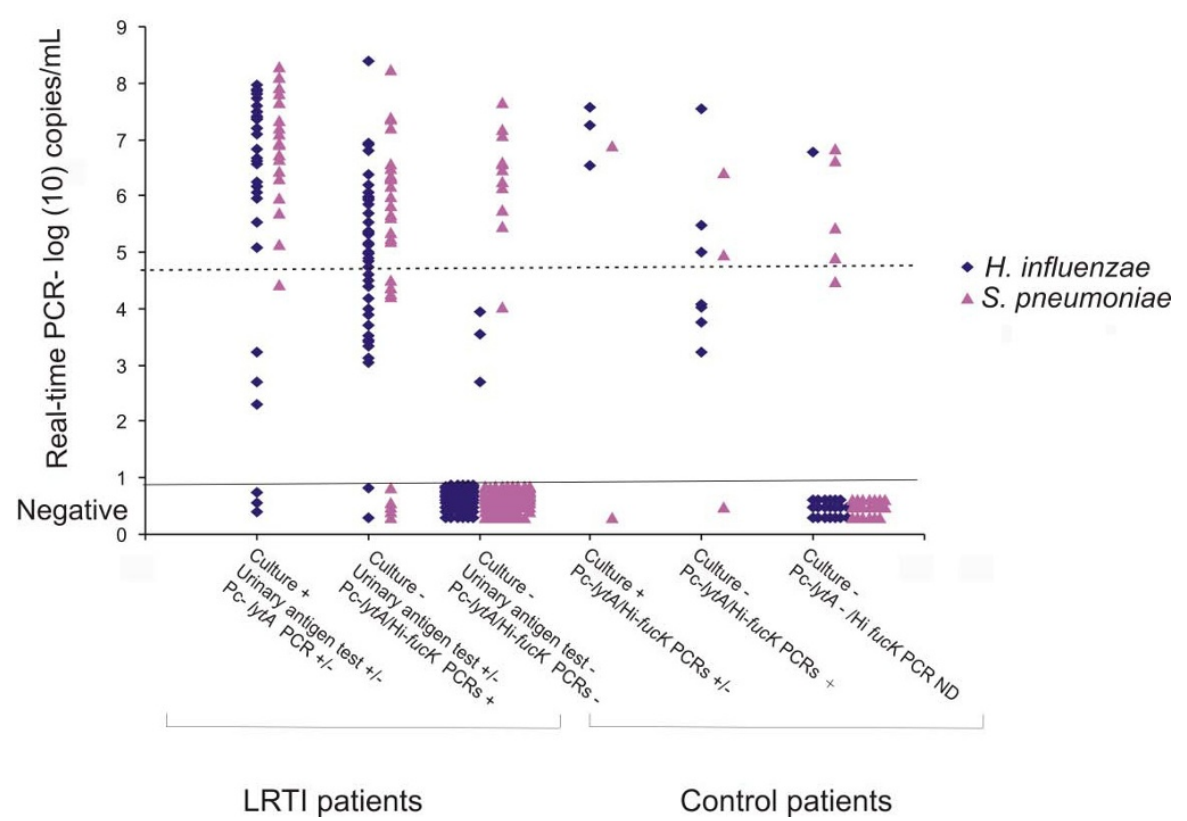

Figure 1 Multiplex real-time PCR copy numbers of target organisms in patients and controls. Comparison of PCR copy numbers in the LRTI patients and controls compared with culture, urinary antigen test and gel-based lytA PCR. 
Table 4 Sensitivities and specificities of multiplex real-time PCR for detection of S. pneumoniae and H. influenzae.

\begin{tabular}{|c|c|c|c|c|c|c|c|c|c|}
\hline \multirow[t]{2}{*}{ Species } & \multirow[t]{2}{*}{ Reference test } & \multicolumn{4}{|c|}{ Detection limit of the assay } & \multicolumn{4}{|c|}{ Cutoff $10^{5}$ copies $/ \mathrm{mL}$} \\
\hline & & Sensitivity & Specificity & PPV $^{\mathbf{a}}$ & NPV ${ }^{b}$ & Sensitivity & Specificity & PPV & NPV \\
\hline \multirow[t]{2}{*}{ S. pneumoniae } & $\begin{array}{l}\text { BAL culture, blood culture and urinary } \\
\text { antigen test }\end{array}$ & $\begin{array}{l}95 \% \\
(20 / 21)\end{array}$ & $\begin{array}{l}75 \% \\
(101 / 135)\end{array}$ & $\begin{array}{l}37 \% \\
(20 / 54)\end{array}$ & $\begin{array}{l}99 \% \\
(101 / 102)\end{array}$ & $\begin{array}{l}90 \% \\
(19 / 21)\end{array}$ & $\begin{array}{l}80 \% \\
(108 / 135)\end{array}$ & $\begin{array}{l}41 \% \\
(19 / 46)\end{array}$ & $\begin{array}{l}98 \% \\
(108 / 110)\end{array}$ \\
\hline & $\begin{array}{l}\text { BAL culture, blood culture and urinary } \\
\text { antigen tes + lytA PCR }\end{array}$ & $\begin{array}{l}91 \% \\
(43 / 47)\end{array}$ & $\begin{array}{l}89 \% \\
(97 / 109)\end{array}$ & $\begin{array}{l}78 \% \\
(43 / 55)\end{array}$ & $\begin{array}{l}96 \% \\
(97 / 101)\end{array}$ & $\begin{array}{l}79 \% \\
(37 / 47)\end{array}$ & $\begin{array}{l}95 \% \\
(104 / 109)\end{array}$ & $\begin{array}{l}88 \% \\
(37 / 42)\end{array}$ & $\begin{array}{l}91 \% \\
(104 / 114)\end{array}$ \\
\hline \multirow[t]{2}{*}{ H. influenzae } & BAL culture ${ }^{c}$ & $\begin{array}{l}90 \% \\
(28 / 31)\end{array}$ & $\begin{array}{l}65 \% \\
(81 / 125)\end{array}$ & $\begin{array}{l}39 \% \\
(28 / 72)\end{array}$ & $\begin{array}{l}96 \% \\
(81 / 84)\end{array}$ & $\begin{array}{l}81 \% \\
(25 / 31)\end{array}$ & $\begin{array}{l}85 \% \\
(106 / 125)\end{array}$ & $\begin{array}{l}57 \% \\
(25 / 44)\end{array}$ & $\begin{array}{l}95 \% \\
(106 / 112)\end{array}$ \\
\hline & BAL culture ${ }^{c}+$ fuck PCR & $\begin{array}{l}93 \% \\
(69 / 74)\end{array}$ & $\begin{array}{l}96 \% \\
(79 / 82)\end{array}$ & $\begin{array}{l}96 \% \\
(69 / 72)\end{array}$ & $\begin{array}{l}94 \% \\
(79 / 84)\end{array}$ & $\begin{array}{l}63 \% \\
(47 / 74)\end{array}$ & $\begin{array}{l}100.0 \% \\
(82 / 82)\end{array}$ & $\begin{array}{l}100 \% \\
(47 / 47)\end{array}$ & $\begin{array}{l}75 \% \\
(82 / 109)\end{array}$ \\
\hline
\end{tabular}

a Positive predictive value

${ }^{\mathrm{b}}$ Negative predictive value

' Blood culture were also performed for $\mathrm{H}$. influenzae but all were negative

${ }^{d}$ fucK PCR was performed in the PCR positive and culture negative samples

Analysis of bronchoalveolar lavage from 156 adults with lower respiratory tract infection.

the patient group the positivity rate would drop from $35 \%(54 / 156)$ to $30 \%(47 / 156)$ for S. pneumoniae and from $46 \%(72 / 156)$ to $20 \%(31 / 156)$ for $H$. influenzae.

Table 4 shows the sensitivities and specificities of the qmPCR, with the detection limit of the PCR assay itself and a detection limit of $10^{5}$ copies $/ \mathrm{mL}$. Since one urinary antigen test positive patient had Spn9802 DNA determined at $<10^{5}$ copies $/ \mathrm{mL}$ and three culture positive patients had P6 DNA determined at $<10^{5}$ copies $/ \mathrm{mL}$, the raise of the cut-off limit to $10^{5}$ copies $/ \mathrm{mL}$, would drop the sensitivities, but the specificities would increase.
Among 103 patients treated with antibiotic before sampling, S. pneumoniae and $H$. influenzae were identified by culture in $6 \%(6 / 103)$ and $20 \%(21 / 103)$ respectively, and by qmPCR in 36\% (37/103) and 53\% (55/103) respectively. Of 22 patients positive by Spn9802 PCR and lytA PCR alone 19 of them had antibiotics prior to sampling.

Figure 2 shows the quantitative results of the qmPCR compared to semi-quantitative culture of BAL specimens for S. pneumoniae and $H$. influenzae. There was no correlation between the measured DNA copy number $/ \mathrm{mL}$ and the bacterial growth.

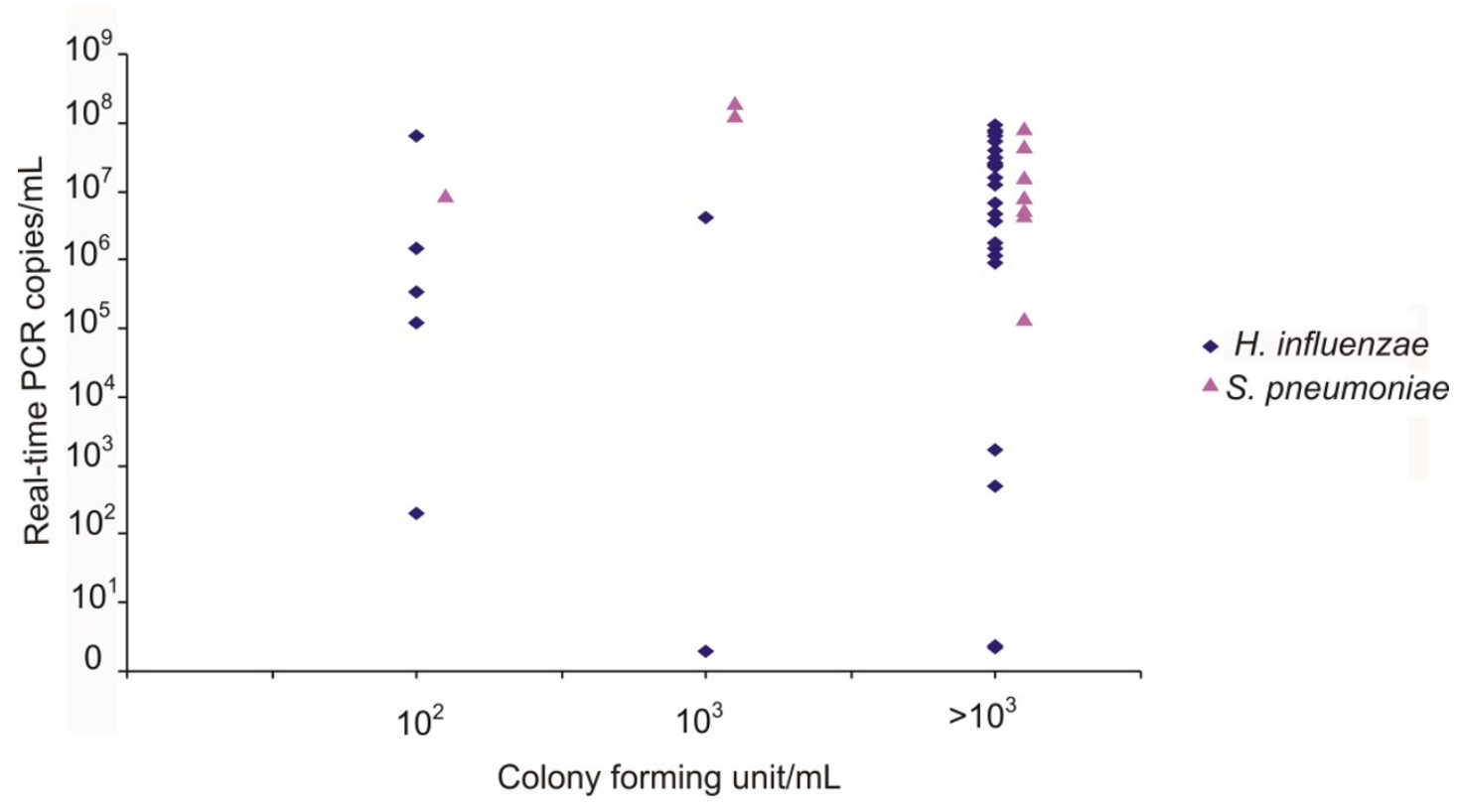

Semi-quantitative growth of S. pneumoniae and $H$. influenzae

Figure 2 Quantitative results of the multiplex real-time PCR compared to semi-quantitative culture of BAL specimens. 
Table 5 shows results of tests for S. pneumoniae and $N$. meningitidis in patients with meningitis. Of 87 CSF samples, S. pneumoniae and $N$. meningitidis were detected by culture in $5(6 \%)$ and $2(2 \%)$ samples, by 16 $S$ rRNA PCR in $14(16 \%)$ and 10 (11\%) and by qmPCR and in $14(16 \%)$ and $10(11 \%)$ samples respectively. Altogether, culture, $16 S$ rRNA PCR and qmPCR were positive for $S$. pneumoniae in 14 cases, $N$. meningitidis in 10 cases, and $H$. influenzae in no case. If culture and the $16 S$ rRNA PCR in combination were used as reference standard for aetiology of meningitis, the sensitivities and specificities would be $100 \%$ and $100 \%$ for both S. pneumoniae and N. meningitidis. Two samples positive by the $\operatorname{ctr} A$ PCR were positive in the unspecific 16 $S$ rRNA PCR and sequence analysis of the PCR product determined them as Neisseria spp. They were considered as $N$. meningitidis in the specificity calculation. Of 17 samples that were negative by culture but positive by qmPCR 8 samples originated from patients that were under antibiotic treatment (Amoxyclav PO, Cefotaxime IV or Cefuroxime IV) before lumbar puncture.

\section{Discussion}

In this study we established a sensitive detection system that enabled simultaneous quantification of S. pneumoniae, $H$. influenzae and $N$. meningitidis DNA using qmPCR. The multiplex assay was reproducible and no change in detection and quantification capacity was seen when a combined mixture of reagents and a combined DNA standard (S. pneumoniae/H. influenzae/N. meningitidis) in single tubes was used (Table 2). This multiplex PCR assay reduced the expense of reagents and the required time for analysis.

Antibiotic treatment prior sampling has been found to reduce the positivity rate of BAL culture from $92 \%$ to $55 \%$ in patients with severe community acquired pneumonia [6]. In this study $66 \%(103 / 156)$ of the patients had antibiotic therapy prior the sampling, this high rate of antibiotic treatment is probably the reason for the suboptimal specificity of the qmPCR. Of 78 samples which were negative by culture and positive for $S$. pneumoniae or $H$. influenzae by the qmPCR, 64 were treated with antibiotic 0-7 days prior to sampling. The high rate of prior antibiotic treatment was probably also the reason for the lack of correlation between DNA concentration and bacterial concentration determined by semiquantitative culture (Figure 2). This lack of correlation between quantification of target DNA and culture contrasts to our previous analysis of nasopharyngeal aspirates from community acquired pneumonia patients, where a significant correlation was seen, but only $25 \%$ of patients were on antibiotic treatment when samples were collected in the previous study $[17,21]$.

The evaluation of nucleic acid amplification tests by comparison with less sensitive reference methods such as culture is problematic. Several imperfect tests may be used to define a composite reference standard [30]. An alternative way to resolve cases with different test results is to use discrepant analysis where an additional method is used to determine the specimen status. Such analyses have been criticized [31], but is often the most realistic procedure for the evaluation of new methods that are more sensitive than an established reference method. In our study the Spn9802 target was evaluated by a composite reference standard and for the P6 target discrepant analysis was used. This resulted in increased specificity and a higher number of pneumonia cases with defined etiology. As expected the positive predictive values increase with increased specificity, thus with a cut-off limit of $10^{5}$ copies/mL a positive PCR result is very reliable using an extended reference standard.

We have recently shown that Spn9802 PCR and P6 PCR are specific for S. pneumoniae and $H$. influenzae when bacterial strains have been tested.

Nevertheless, colonization of S. pneumoniae and $H$. influenzae in the respiratory tract is problematic for both culture and PCR. To overcome this problem semiquantitative culture is often used. In our study a detection limit of $10^{5}$ DNA copies/mL for positive Spn9802 and P6 PCRs yielded a high specificity but somewhat

Table 5 Results of tests for S. pneumoniae and N. meningitidis in 87 patients with meningitis

\begin{tabular}{|c|c|c|c|c|c|c|}
\hline \multirow{2}{*}{$\begin{array}{l}\text { Bacterial } \\
\text { species }\end{array}$} & \multirow{2}{*}{$\begin{array}{l}\text { Culture and/or microscopic } \\
\text { examination }\end{array}$} & \multirow{2}{*}{$\begin{array}{l}16 \text { S rRNA } \\
\text { PCR }\end{array}$} & \multicolumn{2}{|c|}{ qmPCR } & \multirow{2}{*}{$\begin{array}{l}\text { Total } \\
\text { number }\end{array}$} & \multirow{2}{*}{$\begin{array}{l}\text { No. on antibiotic } \\
\text { treatment }\end{array}$} \\
\hline & & & $\begin{array}{l}\text { Spn9802 } \\
\text { PCR }\end{array}$ & $\begin{array}{l}\text { ctrA } \\
\text { PCR }\end{array}$ & & \\
\hline \multirow[t]{2}{*}{ S. pneumoniae } & + & + & + & & 5 & 2 \\
\hline & - & + & + & & 9 & 5 \\
\hline \multirow[t]{3}{*}{ N. meningitidis } & + & + & & + & 2 & \\
\hline & - & $++^{a}$ & & + & 8 & 3 \\
\hline & $-b$ & - & - & - & 63 & \\
\hline
\end{tabular}

${ }^{a}$ Neisseria spp DNA was detected by 16 S rRNA PCR in 2 samples and sequence determined as Neisseria spp. Here considered as N. meningitidis

${ }^{\mathrm{b}}$ Negative for $N$. meningitidis and $H$. influenzae 
reduced the sensitivity. Similar results have been seen in previous studies $[6,32,33]$ based on BAL culture and demonstrated that a cut-off of $10^{4}-10^{5} \mathrm{CFU} / \mathrm{mL}$ allow differentiation between colonization and infection of the lower respiratory tract. However, CFU/mL does not automatically correspond to the number of DNA copies $/ \mathrm{mL}$ since several bacteria may aggregate and generate one colony although they constitute several genome equivalents. Furthermore, as described above antibiotic treatment before sampling and smoking habits have an effect on the number of detected bacteria. Thus patient treatment and the patient group characteristics affect the possibility of using quantification to differentiate between colonization and infection.

When the multiplex PCR was applied on CSF samples, our assay was able to detect all the cases of $N$. meningitidis and S. pneumoniae that were found by culture and/ or 16 S PCR in a previous study [24]. The problem of choosing optimal targets for S. pneumonia and $H$. influenzae has been addressed above. The primer pair used for $N$. meningitidis in our assay has previously been used in a multiplex assay for detection of bacterial meningitis [14] and even been evaluated in a major interlaboratory comparison of PCR-based identification of meningococci [34] as well as in other studies with satisfying results $[35,36]$.

\section{Conclusions}

Although culture is still indispensable in bacteriological diagnostics multiplex PCR enables concurrent diagnostics of viruses and fungi and provides a powerful tool for analysis. We conclude that the multiplex format of the assay facilitates diagnostics of $S$. pneumoniae, $H$. influenzae and N. meningitidis and is suitable for analysis of both respiratory tract tract and CSF specimens. The assay also enable detection after antibiotic treatment has been installed. Quantification increases the specificity of etiology for pneumonia.

\section{Acknowledgements}

The study was supported by funds from the Uppsala-Örebro Regional Research Council.

\section{Author details \\ 'Section of Clinical Bacteriology, Department of Medical Sciences, Uppsala University, Uppsala, Sweden. ${ }^{2}$ Department of Infectious Diseases, Örebro University Hospital, Örebro, Sweden. ${ }^{3}$ Department of Chest Diseases, Aarhus University Hospital, Aalborg, Denmark. ${ }^{4}$ Section of Clinical Virology, Department of Medical Sciences, Uppsala University, Uppsala, Sweden. ${ }^{5}$ Department of Clinical Bacteriology, Sahlgrenska University Hospital, Gothenburg, Sweden.}

\section{Authors' contributions}

$\mathrm{GA}$ : BH, KS and JB have planned the study; GA has done the laboratory work and written the draft. KS, JK and CW have provided clinical materials. All authors have contributed intellectually during the writing process and have read and approved the final manuscript.
Received: 7 June 2010 Accepted: 3 December 2010

Published: 3 December 2010

\section{References}

1. File TM: Community-acquired pneumonia. Lancet 2003, 362:1991-2001.

2. Lode HM: Managing community-acquired pneumonia: a European perspective. Respir Med 2007, 101:1864-1873.

3. Koedel U, Scheld WM, Pfister HW: Pathogenesis and pathophysiology of pneumococcal meningitis. Lancet Infect Dis 2002, 2:721-736.

4. Peltola $\mathrm{H}$ : Worldwide Haemophilus influenzae type $\mathrm{b}$ disease at the beginning of the 21st century: global analysis of the disease burden 25 years after the use of the polysaccharide vaccine and a decade after the advent of conjugates. Clin Microbiol Rev 2000, 13:302-317.

5. Stephens DS: Conquering the meningococcus. FEMS Microbiol Rev 2007, 31:3-14.

6. Dalhoff K, Braun J, Hollandt H, Lipp R, Wiessmann KJ, Marre R: Diagnostic value of bronchoalveolar lavage in patients with opportunistic and nonopportunistic bacterial pneumonia. Infection 1993, 21:291-296.

7. Greiner O, Day PJ, Bosshard PP, Imeri F, Altwegg M, Nadal D: Quantitative detection of Streptococcus pneumoniae in nasopharyngeal secretions by real-time PCR. J Clin Microbiol 2001, 39:3129-3134.

8. Saukkoriipi A, Leskela K, Herva E, Leinonen M: Streptococcus pneumoniae in nasopharyngeal secretions of healthy children: comparison of realtime PCR and culture from STGG-transport medium. Mol Cell Probes 2004, 18:147-153.

9. Yang S, Lin S, Khalil A, Gaydos C, Nuemberger E, Juan G, Hardick J, Bartlett JG, Auwaerter PG, Rothman RE: Quantitative PCR assay using sputum samples for rapid diagnosis of pneumococcal pneumonia in adult emergency department patients. J Clin Microbiol 2005, 43:3221-3226.

10. Marty A, Greiner O, Day PJ, Gunziger S, Muhlemann K, Nadal D: Detection of Haemophilus influenzae type b by real-time PCR. J Clin Microbiol 2004, 42:3813-3815.

11. Ohkusu K, Nash KA, Inderlied CB: Molecular characterisation of Haemophilus influenzae type a and untypeable strains isolated simultaneously from cerebrospinal fluid and blood: novel use of quantitative real-time PCR based on the cap copy number to determine virulence. Clin Microbiol Infect 2005, 11:637-643.

12. Smith-Vaughan $H$, Byun R, Nadkarni M, Jacques NA, Hunter N, Halpin $S$, Morris PS, Leach AJ: Measuring nasal bacterial load and its association with otitis media. BMC Ear Nose Throat Disord 2006, 6:10

13. Taha MK, Fox A: Quality assessed nonculture techniques for detection and typing of meningococci. FEMS Microbiol Rev 2007, 31:37-42.

14. Corless CE, Guiver M, Borrow R, Edwards-Jones V, Fox AJ, Kaczmarski EB: Simultaneous detection of Neisseria meningitidis, Haemophilus influenzae, and Streptococcus pneumoniae in suspected cases of meningitis and septicemia using real-time PCR. J Clin Microbiol 2001 . 39:1553-1558.

15. Deutch $\mathrm{S}$, Moller JK, Ostergaard L: Combined assay for two-hour identification of Streptococcus pneumoniae and Neisseria meningitidis and concomitant detection of $16 \mathrm{~S}$ ribosomal DNA in cerebrospinal fluid by real-time PCR. Scand J Infect Dis 2008, 40:607-614.

16. Hedberg ST, Olcen P, Fredlund H, Molling P: Real-time PCR detection of five prevalent bacteria causing acute meningitis. APMIS 2009, 117:856-860

17. Abdeldaim GM, Stralin K, Olcen P, Blomberg J, Herrmann B: Toward a quantitative DNA-based definition of pneumococcal pneumonia: a comparison of Streptococcus pneumoniae target genes, with special reference to the Spn9802 fragment. Diagn Microbiol Infect Dis 2008, 60:143-150.

18. Verhelst R, Kaijalainen T, De Baere T, Verschraegen G, Claeys G, Van Simaey L, De Ganck C, Vaneechoutte M: Comparison of five genotypic techniques for identification of optochin-resistant pneumococcus-like isolates. J Clin Microbiol 2003, 41:3521-3525.

19. Whatmore AM, Efstratiou A, Pickerill AP, Broughton K, Woodard G Sturgeon D, George R, Dowson CG: Genetic relationships between clinical isolates of Streptococcus pneumoniae, Streptococcus oralis, and Streptococcus mitis: characterization of "Atypical" pneumococci and organisms allied to S. mitis harboring S. pneumoniae virulence factorencoding genes. Infect Immun 2000, 68:1374-1382. 
20. Sam IC, Smith M: Failure to detect capsule gene bexA in Haemophilus influenzae types e and $f$ by real-time PCR due to sequence variation within probe binding sites. J Med Microbiol 2005, 54(Pt 5):453-455.

21. Abdeldaim GM, Stralin K, Kirsebom LA, Olcen P, Blomberg J, Herrmann B: Detection of Haemophilus influenzae in respiratory secretions from pneumonia patients by quantitative real-time polymerase chain reaction. Diagn Microbiol Infect Dis 2009, 64:366-373.

22. Molling $P$, Jacobsson $S$, Backman A, Olcen P: Direct and rapid identification and genogrouping of meningococci and porA amplification by LightCycler PCR. J Clin Microbiol 2002, 40:4531-4535.

23. Stralin K, Korsgaard J, Olcen P: Evaluation of a multiplex PCR for bacterial pathogens applied to bronchoalveolar lavage. Eur Respir J 2006, 28:568-575.

24. Welinder-Olsson C, Dotevall $L$, Hogevik H, Jungnelius R, Trollfors B, Wahl M, Larsson P: Comparison of broad-range bacterial PCR and culture of cerebrospinal fluid for diagnosis of community-acquired bacterial meningitis. Clin Microbiol Infect 2007, 13:879-886.

25. Nielsen SV, Henrichsen J: Detection of pneumococcal polysaccharide antigens in the urine of patients with bacteraemic and non-bacteraemic pneumococcal pneumonia. Zentralb/ Bakteriol 1994, 281:451-456.

26. WHO: Laboratory methods for the diagnosis of meningitis caused by Neisseria meningitidis, Streptococcus pneumoniae, and Haemophilus influenzae. WHO Communicable disease surveillance and response 2008 Report No.: WHO/CDS/CSR/EDC/99.97

27. Braasch DA, Corey DR: Locked nucleic acid (LNA): fine-tuning the recognition of DNA and RNA. Chem Biol 2001, 8:1-7.

28. Meats E, Feil EJ, Stringer S, Cody AJ, Goldstein R, Kroll JS, Popovic T, Spratt BG: Characterization of encapsulated and noncapsulated Haemophilus influenzae and determination of phylogenetic relationships by multilocus sequence typing. J Clin Microbiol 2003, 41:1623-1636.

29. Stralin K, Backman A, Holmberg H, Fredlund H, Olcen P: Design of a multiplex PCR for Streptococcus pneumoniae, Haemophilus influenzae, Mycoplasma pneumoniae and Chlamydophila pneumoniae to be used on sputum samples. APMIS 2005, 113:99-111.

30. Rutjes AW, Reitsma JB, Coomarasamy A, Khan KS, Bossuyt PM: Evaluation of diagnostic tests when there is no gold standard. A review of methods. Health Technol Assess 2007, 11:iii, ix-51.

31. Hadgu A: Discrepant analysis: a biased and an unscientific method for estimating test sensitivity and specificity. J Clin Epidemio/ 1999, 52(12):1231-1237.

32. Kahn FW, Jones JM: Diagnosing bacterial respiratory infection by bronchoalveolar lavage. J Infect Dis 1987, 155:862-869.

33. Thorpe JE, Baughman RP, Frame PT, Wesseler TA, Staneck JL: Bronchoalveolar lavage for diagnosing acute bacterial pneumonia. $J$ Infect Dis 1987, 155:855-861.

34. Taha MK, Alonso JM, Cafferkey M, Caugant DA, Clarke SC, Diggle MA, Fox A, Frosch M, Gray SJ, Guiver M, et al: Interlaboratory comparison of PCRbased identification and genogrouping of Neisseria meningitidis. J Clin Microbiol 2005, 43:144-149.

35. Fernandez-Rodriguez A, Alcala B, Alvarez-Lafuente R: Real-time polymerase chain reaction detection of Neisseria meningitidis in formalin-fixed tissues from sudden deaths. Diagn Microbiol Infect Dis 2008, 60:339-346.

36. Gray SJ, Trotter CL, Ramsay ME, Guiver M, Fox AJ, Borrow R, Mallard RH, Kaczmarski EB: Epidemiology of meningococcal disease in England and Wales 1993/94 to 2003/04: contribution and experiences of the Meningococcal Reference Unit. J Med Microbiol 2006, 55(Pt 7):887-896.

doi:10.1186/1471-2180-10-310

Cite this article as: Abdeldaim et al:: Multiplex quantitative PCR for detection of lower respiratory tract infection and meningitis caused by Streptococcus pneumoniae, Haemophilus influenzae and Neisseria meningitidis. BMC Microbiology 2010 10:310.

\section{Submit your next manuscript to BioMed Central and take full advantage of:}

- Convenient online submission

- Thorough peer review

- No space constraints or color figure charges

- Immediate publication on acceptance

- Inclusion in PubMed, CAS, Scopus and Google Scholar

- Research which is freely available for redistribution

Submit your manuscript at www.biomedcentral.com/submit
Ciomed Central 